\title{
Conductas de riesgo social y de salud en adolescentes. Propuesta de intervención contextualizada para un caso de bullying
}

\author{
Fuensanta Cerezo* e Inmaculada Méndez
}

Universidad de Murcia

\begin{abstract}
Resumen: La vivencia de situaciones de riesgo social forma parte de un comportamiento ampliamente compartido entre adolescentes. Entre estas conductas destacan el abuso de sustancias adictivas y los problemas de relación familiar y escolar, con especial mención al bullying, que se perfila, cada vez con mayor claridad, como una disfunción social.

El trabajo que aquí presentamos plantea (1) el análisis de diversas conductas de riesgo social y de bienestar personal en adolescentes $(N=1239)$ estudiantes de educación secundaria obligatoria (612 chicos y 627 chicas) y, (2) una propuesta contextualizada de intervención en un grupo aula $(n=27)$, donde se detectaron 2 alumnos agresores, 2 víctimas y 1 alumno víctimaprovocador.

Los resultados indican que más del 25\% de alumnos realizan acciones con riesgo social y para su salud, destacando el consumo de drogas y conducir bajo los efectos del alcohol. Las tasas de consumo son similares para chicos y chicas, y mayor entre los chicos para otras acciones de riesgo. Así mismo, encontramos una alta relación entre las diferentes conductas de riesgo, fracaso escolar y participación en bullying.

El análisis del grupo aula intacto reveló que los agresores presentan un elevado fracaso escolar y realizan actividades predelictivas que encuentran apoyo en sus amigos y familiares. La propuesta de intervención para este grupo va dirigida no solo a los implicados, sino también a los diferentes agentes educativos.

Palabras clave: riesgo social; consumo de drogas; fracaso escolar; adolescencia; bullying; programa intervención; relaciones interpersonales.

Title: Social and health risk behaviours in adolescents. Context intervention proposal for a bullying case.

Abstract: Social and personal risk behaviours are extending behaviours among adolescents. Drugs abuse and problems in family and school relationships stand out among these behaviours, where bullying is detected, every time more, as a social dysfunction.

This paper presents (1) the analysis of some social and personal well being risk behaviour among adolescents $(\mathrm{N}=1239)$ secondary school pupils, $(612$ boys and 627 girls) and (2) a context intervention proposal for a classgroup ( $\mathrm{n}=27$ ), where bullying were detected performed by 2 bullies, 2 victims and 1 provoke-victim pupils.

Findings point out that, more than one in four pupils shows social and health risk behaviour, such as drugs abuse or drive under alcoholics' effects. We did not find differences in drugs consume between boys and girls but boys score higher in other risk behaviours. We also observed high relations among risk behaviours, scholar failure and bullying.

Analysis for the intact group-class revealed that bully pupils present a high level of scholar failure and perpetrate other delinquent actions and they find support in their friends and family. The intervention proposal for this group is oriented not only for those pupils involved in bullying, but also for all educative agents.

Key words: Social risk; drugs consume; scholar failure; adolescence; bullying; intervention program; interpersonal relationships.
\end{abstract}

\section{Introducción}

La adolescencia es una etapa del ciclo vital con profundos cambios físicos, psicológicos y cognitivos durante la cual el afán por experimentar sensaciones nuevas puede suponer amenazas a la salud o riesgos al bienestar personal (Estévez y Emler, 2011). Con frecuencia se trata de un periodo crítico en el inicio y experimentación de conductas de riesgo (Cava, Murgui y Musitu, 2008) y, de hecho, en las sociedades occidentales, un porcentaje significativo de adolescentes muestra algún tipo de conducta antisocial durante estos años ( $\mathrm{Fa}$ rrington, 2005).

Entendemos por conducta antisocial (CAS) a los procesos que conducen a los jóvenes a involucrarse en comportamientos delictivos como: agresión a personas y animales, destrucción de la propiedad, fraudulencia o robo y transgresiones graves de las normas (APA, 2000). Se incluyen, junto a comportamientos delictivos, otras conductas antinormativas que, no son ilegales pero, se consideran dañinas para la sociedad y por tanto son motivo de sanción (Luengo, Otero, Romero, Gómez y Tavares, 1999). Su característica esencial es que se trata de un patrón de comportamiento persistente y repetitivo en el cual se violan los derechos básicos de los otros o importantes normas sociales adecuadas a la edad del sujeto. Estudios sobre estas conductas en la adolescencia en-

* Dirección para correspondencia [Correspondence address]: Fuensanta Cerezo. Universidad de Murcia. Facultad de Psicología. Campus de Espinardo. 30100, Murcia (España).E-mail: fcerezo@um.es cuentran alta relación con factores de riesgo psicosocial como el consumo de alcohol y tabaco (Inglés, et. al, 2007). En su conjunto, las CAS suelen asociarse a un temprano inicio en el consumo de drogas, a la realización de actos temerarios y peligrosos (López y López, 2008) y al uso de la violencia en las relaciones interpersonales (Farrington, 2005).

Las encuestas sobre consumo de drogas en población escolar, señalan que ésta es una de las amenazas a la salud más destacadas durante la adolescencia (Sánchez, Moreno, Muñoz y Pérez, 2007) y que es en este periodo cuando se inicia el abuso de las mismas (Becoña, 2000). En España, la Delegación del Gobierno para el Plan Nacional sobre Drogas (DGPNSD, 2009) en su informe apunta los siguientes datos sobre consumo en jóvenes de 14 a 18 años: el 23\% consume alcohol los fines de semana de manera habitual; del mismo modo el $20 \%$ consume cannabis; usa tranquilizantes sin receta médica el $9.4 \%$ y el $9.5 \%$ conduce un vehículo bajo los efectos del alcohol. Otros estudios señalan que en lo referente al consumo de varias sustancias adictivas o policonsumo, casi la totalidad de los adolescentes que habían consumido alcohol, también habían consumido cannabis. Así mismo destacan que la edad de inicio en el consumo de drogas se sitúa entre los 13 y 14 años, -sobre todo de tabaco y alcohol, y que la tasa de consumo aumenta durante los años de la adolescencia (Ruiz-Juan y Ruiz-Risueño, 2011). En cuanto al consumo según sexo, en las drogas legales (tabaco, alcohol y tranquilizantes) destacan las chicas mientras que los varones destacan en los otros casos. Estos datos evidencian que estamos ante un problema extendido entre los 
jóvenes de ambos sexos que conceden escasa importancia a sus efectos, minimizando sus consecuencias negativas para la salud. Las cifras son alarmantes si tenemos en cuenta que las situaciones de riesgo personal y social entre los adolescentes pueden ser consideradas como precedentes de un patrón continuo de comportamiento delictivo o antisocial en la vida adulta (Renda, Vassallo y Edwards, 2011), e incluso del posterior consumo habitual de sustancias adictivas (Kim, Catalano, Haggerty y Abbott, 2011).

De otro lado, las situaciones más preocupantes en el ámbito escolar son las relativas a la agresividad ente iguales conocido internacionalmente como bullying-. Se trata de una forma de maltrato intencionado que ejerce un estudiante o grupo de ellos, hacia otro compañero al que convierten en su víctima habitual (Olweus,1993). Es un fenómeno que se detecta en todos los centros escolares con independencia de su titularidad (AA.VV., 2007) y lugar (Cerezo y Ato, 2005). Su efectos son muy negativos en los agresores ya que afianzan su conducta agresiva (Bender y Lösel, 2011) y acarrean graves consecuencias físicas, psicológicas y sociales para la víctima (Lösel y Bender, 2011). En España, el segundo informe del Defensor del Pueblo (AA.VV., 2007) sobre violencia escolar apunta que, desde la perspectiva de los observadores o testigos, las situaciones de acoso entre escolares más habituales son, en primer lugar, la agresión verbal, como poner motes ofensivos $(55.8 \%)$ o insultar $(54.7 \%)$, seguida por la agresión física directa (14.2\%). Desde la Organización para la Cooperación Económica y el Desarrollo -OCDE-, en su Estudio Internacional sobre Enseñanza y Aprendizaje, TALIS (Teaching and Learning Internacional Survey) de 2009, apunta que los problemas de convivencia en las aulas en nuestro país se sitúan por encima de la media internacional, destacando: conductas perturbadoras (70.5\%), vandalismo (28\%), intimidación verbal o abuso a compañeros (40.6\%), y uso o posesión de drogas (20.3\%). Un efecto asociado a este fenómeno es que no solo implica la díada agresor-victima sino a toda la comunidad educativa (Salmivalli, 2010), lo que ha provocado una alta preocupación institucional y social.

Algunos estudios relacionan las conductas bullying con otras conductas antisociales y al consumo de drogas (Becoña et al., 2011; Farrington y Ttofi, 2011). Investigaciones previas llevadas a cabo por las autoras pusieron de manifiesto una alta asociación entre participación en bullying y otras conductas de riesgo, encontrando que los agresores asumen conductas predelictivas y/o conductas de riesgo para su salud, como altos índices de consumo de alcohol y otras drogas; conducir bajo los efectos de las drogas, haber sido detenido por las fuerzas del orden público y ser expulsados del centro educativo, mientras que en las víctimas se aprecia un mayor consumo de tranquilizantes sin receta médica (Méndez y Cerezo, 2010).

Es evidente que la sociedad en su conjunto está mas sensibilizada ante las conductas problemáticas de los adolescentes, lo que ha llevado en los últimos años, al desarrollo de programas de prevención e intervención, por un lado hacia la drogadicción (Becoña, 2000; Gázquez, García del Castillo y Espada, 2011) y también hacia el bullying (Garaigordobil y Onderreña, 2008), aunque como señalan Serrano e Iborra, con un marcado carácter sancionador, dado que apenas se registran actuaciones que persigan la restitución o la aplicación de acciones educativas y/o terapéuticas (Serrano e Iborra, 2005). El informe del Defensor del Pueblo (AA.VV. 2007) sobre violencia escolar en la educación secundaria, en la misma línea, concluye que, las políticas preventivas y las líneas de intervención que se han seguido logran ciertos resultados parciales, pero claramente insuficientes, en la medida en que sólo alivian pero en absoluto resuelven el problema. Estas conclusiones han llevado a solicitar que todos los centros escolares inserten en su plan de centro medidas específicas para mejorar la convivencia escolar. Desde la investigación, igualmente, se ha desarrollado programas con este fin, como el denominado "alumno ayudante" de Fernandez, Villaoslada y Funes (2002), o los propuestos por Ortega y Mora-Merchán (2005), Díaz-Aguado (2006), Monjas (2000) o Trianes y Fernandez-Figarés (2001). Entre ellos hemos seleccionado el programa CIP Concienciar, Informar y Prevenir (Cerezo, Calvo y Sánchez, 2011), específico para la intervención psicoeducativa y tratamiento diferenciado del bullying. Este programa, resultado de numerosas intervenciones de carácter grupal e individual, tiene como punto de partida la concienciación del problema y el análisis de la realidad escolar. Se plantea como una serie de estrategias coordinadas que requieren de la implicación de todos los niveles de la comunidad escolar, a través de la aplicación de pautas y estrategias de prevención ajustadas a las necesidades detectadas.

El estudio que ahora presentamos, en la línea de los precedentes, realizado con una muestra de adolescentes mas amplia que aquellos y atendiendo a la necesidad de proporcionar estrategias de actuación específicas, analiza las siguientes formas de comportamiento antisocial (CAS): grado excesivo de peleas o intimidaciones; conducir o ser pasajero de un vehículo de motor bajo los efectos del alcohol; ser detenido por las fuerzas de orden público; tener un conflicto o discusión importante con padres o hermanos; escapar de casa durante más de un día completo y ser expulsado del centro educativo durante un día completo o más. Se ha evaluado la tasa de consumo (TC) de cigarrillos, bebidas alcohólicas, tranquilizantes, hachís y otras drogas; y la tasa de policonsumo (TPC), consumo de una droga sin haber pasado más de dos horas de haber consumido otra, ambas desde la perspectiva de un consumo habitual. La implicación en bullying, siguiendo la clasificación propuesta en el Test Bull-S (Cerezo, 2002), establece 4 roles: Neutro o no implicado, agresivo, víctima, y víctima-provocador.

El segundo aspecto de este trabajo se centra en la evaluación y propuestas de intervención para un grupo-aula, donde se han tenido en cuenta las variables que suelen estar presentes en los estudios sobre violencia en adolescentes, es decir, las relativas al entorno familiar (Inglés et al, 2007), como la reacción de los padres ante el consumo, el consumo 
por parte de los padres, el control familiar, si el chico o la chica ha sido informado en su familia de los riesgos del consumo y la percepción de las relaciones con los padres y hermanos. En cuanto a los factores de riesgo escolar se ha tenido en cuenta el fracaso escolar, la procedencia (español o extranjero), la implicación en la dinámica bullying y las conductas de riesgo. Se presta especial atención a las conductas de riesgo social y para la salud del grupo de amigos y la pertenencia a un grupo de iguales conflictivo (Alonso, HuedoMedina y Espada, 2009). Para el análisis de las características del sujeto agresor, hemos considerado además, la percepción de vulnerabilidad global que incluye aspectos del entorno social familiar sobre las actitudes educadoras parentales (Bender y Lösel, 2011; Torrente y Rodríguez, 2004) y del grupo de amigos (Pérez y Gázquez, 2010); la inadaptación general, personal, familiar y escolar; la situación sociométrica en el grupo de iguales (Cerezo y Ato, 2010) y la percepción que el grupo tiene sobre el propio sujeto y otras características asociadas al rol de agresor.

El trabajo persigue tres objetivos principales: el primero, conocer la situación de riesgo social, medido a través de conductas predelictivas (CAS) y la situación de riesgo personal, según el grado de consumo de sustancias adictivas, según TC y TPC, en jóvenes adolescentes, en función del sexo y edad. Como segundo objetivo nos proponemos indagar en la posible relación entre estas conductas de riesgo y el fracaso escolar (repetición de curso) y el rol asociado al bullying (agresor, víctima o víctima-provocador). Por último, derivado de los anteriores, tras el análisis pormenorizado de un grupo-aula intacto, proponer un programa de intervención contextualizado, que aporte estrategias orientadas hacia el sujeto agresor, el conjunto grupo-aula, el profesor tutor del grupo y los padres.

\section{Método}

\section{Sujetos}

La muestra global del estudio está compuesta por 1239 estudiantes de educación secundaria obligatoria (612 hombres y 627 mujeres), de edades comprendidas entre los 11-18 años y una edad media de 14.39 (DT $=1.435)$, pertenecientes a centros públicos $(\mathrm{n}=10)$ y privados o concertados $(n=3)$ de la Región de Murcia, durante los cursos académicos 2008-2009 y 2009-2010. La distribución por nivel académico fue: $28.6 \%(\mathrm{n}=354)$ en primer curso, $16.5 \%$ $(n=204)$ en segundo curso, 24.1\% $(n=299)$ en tercer curso y $30.8 \%(n=382)$ en cuarto curso.

Partiendo de la muestra global, se seleccionó un grupoaula intacto compuesto por 27 estudiantes de $4^{\circ}$ de la ESO de un centro educativo de carácter público situado en la periferia de la ciudad de Murcia, cuyas edades se situaban en un rango de entre 15-17 años, siendo 11 hombres y 20 mujeres. El análisis del grupo-aula permitió detectar a 4 estudiantes implicados directamente en la problemática bullying: 2 sujetos agresores (uno de ellos con problemas conductuales acentuados y el otro en situación de riesgo), 1 sujeto víctima y 1 sujeto víctima-agresor, siendo la tasa de implicados de $14.81 \%$.

\section{Instrumentos}

La valoración de las conductas en el conjunto de la muestra se realizó a través de instrumentos contrastados en la población española. Así, para los datos sobre conductas de riesgo social y para la salud se utilizó la "Encuesta estatal sobre uso de drogas en estudiantes de Enseñanzas Secundarias (ESTUDES)", promovida por la Delegación del Gobierno para el Plan Nacional sobre Drogas (2008), adaptada por Cerezo, Méndez y Rabadán (2009). Este cuestionario consta de 82 ítems (preguntas dicotómicas y politómicas) e indaga sobre: características sociodemográficas, consumo de drogas, problemas ocurridos en los últimos 12 meses, hábitos deportivos y salud y percepción de la convivencia escolar. Del conjunto de ítems hemos seleccionado aquellos que se refieren a características sociodemográficas y académicas (4): Edad, sexo, fracaso escolar y procedencia; Factor consumo (7): consumo de sustancias adictivas que constituyen un riesgo para la salud, teniendo en cuenta que no se trata de un consumo esporádico; Factor policonsumo (2): Bebidas alcohólicas y cannabis y Bebidas alcohólicas y cocaína y Factor conducta antisocial (CAS) (7): conductas que muestran agresividad y desafío a las normas (véase Tabla 1). El índice de fiabilidad para el conjunto de los elementos seleccionados en estos tres factores, medido a través del alfa de Cronbach, es de .681 .

Tabla 1. Variables de Consumo y Conducta Antisocial

Variables de Consumo

Cigarrillos de tabaco diariamente

Bebidas alcohólicas prácticamente todas las semanas

Emborracharse prácticamente todas las semanas

Tranquilizantes o pastillas para dormir sin receta médica

Hachís o marihuana

Cocaína

Otra droga

Variables de Riesgo Antisocial (CAS)

Conducir un vehículo de motor bajo los efectos del alcohol.

Ser pasajero de un vehículo de motor conducido bajo los efectos del alcohol.

Participar en alguna pelea o agresión física

Ser detenido por las fuerzas del orden público

Tener un conflicto o discusión importante con padres o hermanos Escapar de casa durante más de un día completo.

$\underline{\text { Ser expulsado del centro educativo durante un día completo o más. }}$

Sobre los datos obtenidos en cada factor se procedió a la creación de unas tasas tras la recodificación de las variables más relevantes del estudio. Así, con las variables del factor consumo, se tuvo en cuenta si el consumo era diario o por el contrario semanal u ocasional, teniendo mas peso el diario frente al ocasional. Las puntuaciones se transformaron según un intervalo que posee un límite inferior de 0 y un límite superior de 7. Para un manejo más adecuado de los 
datos se ha procedido elaborar una la tasa de consumos especificando los siguientes intervalos: No (0), Moderado (12), Alto (3-4) y Muy alto (5-7).

Del mismo modo, se procedió a elaborar la tasa de policonsumo, ésta tuvo en cuenta el número de días (en los últimos 12 meses) en los que se habían consumido dos sustancias sin que hubieran pasado dos horas entre el consumo de una y otra sustancia. En este caso, el límite inferior es $0 \mathrm{y}$ el superior es 2 .

Por último, calculamos el índice de riesgo antisocial (CAS), teniendo en cuenta las distintas variables de riesgo o problemas que el estudiante ha tenido en los últimos 12 meses. Para éste índice, la puntuación oscila entre el límite inferior de 0 y el límite superior de 7. Los intervalos son: No (0), Moderado (1-2), Alto (3-4) y Muy alto (5-7).

La evaluación de las relaciones socioafectivas y la información sobre la incidencia del bullying se realizó a través del Test Bull-S (Cerezo, 2002). Este cuestionario nomimativo, formado por 15 ítems, recoge las valoraciones de cada sujeto en cuanto a nivel de agresión y victimización en su grupo aula -información sobre los sujetos que, en opinión de, al menos el 25\% del grupo, destacan como: agresivos, víctimas o víctima-provocador, siendo neutros los no destacados; sobre el grado de sociabilidad o posición sociométrica, así como aspectos de carácter situacional como frecuencia de las agresiones y formas y lugares de mayor ocurrencia. Por último, recaba información sobre el nivel de seguridad y gravedad percibida en el grupo-aula y en el centro escolar. Presenta una validez global Alfa de Cronbach de .73 , siendo de .83 para los ítems relativos a las conductas de victimización y de .82 para los relativos a las conductas de agresión .82 (Cerezo, 2006, 2009).

Para conocer el nivel de riesgo social en el consumo de drogas, en el grupo-aula seleccionado, se utilizó el cuestionario FRIDA -Factores de Riesgo Interpersonales para el consumo de Drogas en Adolescentes- (Secades, Carballo, Fernández, García Rodríguez y García Cueto, 2006). Su aplicación permite conocer un valor global denominado "Índice de vulnerabilidad global" que informa sobre el nivel de riesgo de consumo de drogas. Sus 90 ítems de respuesta tipo Likert, se agrupan en 7 factores: 1. Reacción de la familia ante el consumo de drogas; 2. Actitud del grupo de amigos ante las drogas, que incluye su nivel de consumo y tipo de actividades que pueden realizar con ellos; 3. Facilidad de acceso a las drogas o percepción que el sujeto tiene sobre este punto; 4. Riesgo familiar, que engloba aspectos relacionados con el trato familiar (cuidado o maltrato), el consumo familiar de drogas y la percepción de conflicto en la familia; 5. Educación familiar, evalúa si el sujeto recibe información sobre drogas en su familia; 6 . Actividades protectoras tales como: la calidad de relación con la familia y aspectos positivos relacionados con el ámbito académico y 7 . Estilo educativo o control familiar, mide la existencia de normas en el seno familiar y quién las establece, permitiendo clasificar el estilo educativo familiar en: democrático, menos democrático o permisivo. El un índice de fiabilidad de Cronbach de .925 para el conjunto de la prueba.

El nivel de adaptación del agresor estudiado en el grupoaula se obtuvo a través del cuestionario TAMAI (Hernández, 2004). Se trata de una prueba autoevaluativa sobre actitudes y comportamientos respecto a sí mismo, a la relación social, al ámbito escolar y familiar y sobre las actitudes educadoras parentales. Consta de 175 ítems de respuesta dicotómica que conforman los siguientes factores: Inadaptación personal, social, escolar, familiar y actitudes educadoras de los padres. La prueba incluye una escala de frabilidad o estilo de realización y otra llamada de "discrepancia educativa" que compara el estilo educativo entre ambos padres, ha demostrado buenas propiedades psicométricas (índice de Fiabilidad de Spearman-Brown de .87) y su utilidad en un amplio rango de niveles educativos.

Por último, la propuesta de intervención se elaboró siguiendo el modelo del Programa CIP (Cerezo, et. al, 2011). El programa CIP se establece a partir de la concienciación del problema y del análisis de la realidad a todos los niveles de la comunidad escolar (Véase figura 1). Las fases del programa se ordenan en: 1. Concienciación del problema: Me doy cuenta; 2. Periodo de análisis de la situación: Analizamos; 3. Concreción de actuaciones y calendario: Elaboramos el Programa; 4. Comunicación del programa y compromiso: Damos a conocer; 5. Puesta en práctica de lo acordado. Actuar y 6. Revisión y seguimiento: Evaluar resultados. El programa se orienta hacia la institución escolar; el profesorado; el alumnado: el grupo-aula; los individuos implicados; las familias en general y especialmente las de los sujetos implicados o en riesgo. El organigrama de la intervención sitúa al profesor tutor del grupo como el principal elemento para la realización del programa (véase Figura 1).

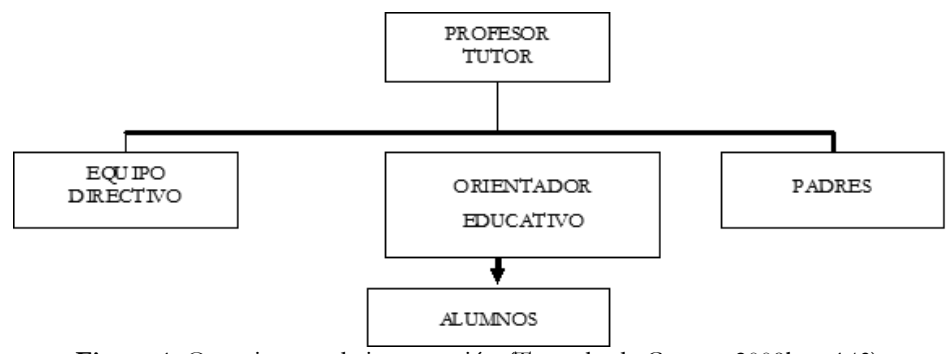

Figura 1. Organigrama de intervención (Tomado de Cerezo, 2009b, p.143). 


\section{Procedimiento}

En primer lugar se solicitó autorización a la Consejería de Educación, Formación y Empleo de la Región de Murcia. A continuación, tras la selección de los centros de Educación Secundaria Obligatoria de carácter público y privado/concertado participantes se llevó a cabo una entrevista con el equipo directivo y el orientador educativo para promover su colaboración, donde se detallaron los objetivos del trabajo, los instrumentos de medida a utilizar y se acordaron las sesiones y aulas necesarias. Se procedió a solicitar la autorización explícita de padres, madres o representantes legales y se informó al Consejo Escolar. Una vez conseguido el consentimiento por escrito comenzamos la recogida de información. Los cuestionarios fueron administrados personal entrenado previamente. Fueron necesarias dos sesiones de 50 minutos (en horario de tutorías) para su cumplimentación. Se informó a los sujetos fueron de la confidencialidad y anonimato de los datos, objetivos de la investigación, y sobre las normas de cumplimentación en las plantillas de respuesta.

Una vez analizados se procedió a la devolución de la información obtenida a través de un informe a los centros educativos participantes del estudio. De entre estos grupos seleccionamos uno intacto para analizar sus características y avanzar la propuesta de intervención, que dadas sus características puede ser considerado como ejemplo, de modo que permite aportar una visión de la realidad de los problemas de conducta en las aulas y al mismo tiempo facilitar una propuesta de intervención global como se propuso al propio centro educativo.

\section{Análisis estadístico de los datos}

Los datos obtenidos fueron codificados y posteriormente introducidos en una base de datos para su tratamiento con el paquete estadístico SPSS (versión 15.0). Los análisis siguieron el siguiente proceso: análisis de datos sobre la muestra global, análisis sobre los datos del grupo-aula y finalmente análisis cualitativo con los datos de un caso. Pasamos a exponer estos análisis.

Análisis de datos de la muestra global. El estudio exploratorio con todos los datos de la muestra para el análisis de la distribución de los mismos, puso de manifiesto la existencia de casos out laiers, pero dado que se trata de un estudio que muestra la realidad social, hemos considerado oportuno mantener los valores anómalos. En el análisis descriptivo incluimos el estudio de frecuencias y porcentajes, a continuación realizamos el análisis de las posibles asociaciones significativas entre las variables. Al tratarse de variables cualitativas se procedió a la elaboración de las tablas de contingencia con la prueba Chi-Cuadrado de Pearson, y por último, y tras la transformación de los datos en las tasas cuantitativas, para conocer el sentido de las diferencias, se utilizó la prueba Anova, con la Prueba post hoc de comparaciones múltiples de Bonferroni. Se optó por utilizar la prueba de Brown-
Forsythe cuando no pudo ser admitida la igualdad de varianzas a través de la prueba de Levene.

Para el análisis sobre los datos del grupo-aula, teniendo en cuenta el reducido número de sujetos, utilizamos un diseño transversal, de tipo descriptivo, con técnicas estadísticas inferenciales. Con estos datos se procedió, en primer lugar, al análisis de los datos globales para el conjunto del grupo, a través del análisis de frecuencias, en segundo lugar, procedimos a los análisis comparativos entre los diferentes subgrupos (neutro, agresor, víctima y víctima-agresor), a través de tablas de contingencia. Para simplificar estos análisis se agruparon las respuestas, bien de manera dicotómica (Si-No) o en tres segmentos ( $\mathrm{Nada}$ o poco; Bastante o Medio y Mucho o Alto).

Por último, se procedió al estudio del caso de un sujeto agresor mediante el análisis cualitativo de los datos proporcionados por el conjunto de las pruebas utilizadas.

Finalmente se realizó la propuesta de intervención contextualizada sobre el grupo-aula analizado.

\section{Resultados}

Los resultados de presentan según el proceso de análisis presentado en el apartado anterior.

Tabla 2. Distribución de la muestra global en frecuencias y porcentajes.

\begin{tabular}{|c|c|c|c|}
\hline Variable & & Frecuencia & Porcentaje \\
\hline \multirow[t]{2}{*}{ Sexo } & Hombre & 612 & $49.4 \%$ \\
\hline & Mujer & 627 & $50.6 \%$ \\
\hline \multirow[t]{3}{*}{ Edad } & $11-13$ & 346 & $27.9 \%$ \\
\hline & $14-15$ & 618 & $49.9 \%$ \\
\hline & $16-18$ & 275 & $22.2 \%$ \\
\hline \multirow[t]{2}{*}{ Procedencia } & Español & 1031 & $83.3 \%$ \\
\hline & Extranjero & 207 & $16.7 \%$ \\
\hline \multirow[t]{3}{*}{ Fracaso escolar } & Repetido un curso & 336 & $27.2 \%$ \\
\hline & Repetido dos cursos & 109 & $8.8 \%$ \\
\hline & No repetidor & 792 & $64 \%$ \\
\hline \multirow[t]{4}{*}{ Problemática Bullying } & Neutro & 998 & $80.5 \%$ \\
\hline & Agresor & 109 & $8.8 \%$ \\
\hline & Víctima & 125 & $10.1 \%$ \\
\hline & Víctima-provocador & 7 & $0.6 \%$ \\
\hline \multirow[t]{4}{*}{ Nivel consumo } & No & 873 & $71.5 \%$ \\
\hline & Moderado & 276 & $22.6 \%$ \\
\hline & Alto & 58 & $4.8 \%$ \\
\hline & Muy alto & 14 & $1.1 \%$ \\
\hline \multirow[t]{5}{*}{ Policonsumo } & No & 966 & $78.5 \%$ \\
\hline & Bajo & 80 & $6.5 \%$ \\
\hline & Moderado & 143 & $11.6 \%$ \\
\hline & Alto & 12 & $1 \%$ \\
\hline & Muy alto & 30 & $2.4 \%$ \\
\hline \multirow[t]{4}{*}{ Conducta antisocial } & No & 527 & $51.7 \%$ \\
\hline & Moderado & 417 & $40.9 \%$ \\
\hline & Alto & 64 & $6.3 \%$ \\
\hline & Muy alto & 11 & $1.1 \%$ \\
\hline
\end{tabular}




\section{Análisis de datos de la muestra global}

Para facilitar la lectura de los datos se ha procedido a establecer intervalos con las diferentes variables, respetando siempre la agrupación pertinente para no perder información relevante (véase Tabla 2). El análisis descriptivo de la muestra sobre las variables sociodemográficas y académicas relevantes (sexo, edad, procedencia y fracaso escolar) pone de manifiesto que, la muestra está bastante equilibrada en cuanto al sexo de los participantes: $49.4 \%$ hombres frente $50.6 \%$ mujeres, que el $16.7 \%(\mathrm{n}=207)$ son de procedencia extranjera y que el $31.5 \%$ de los adolescentes llevan retraso en su formación.

En lo referente a la realización de conductas de riesgo social y para la salud, se aprecia que el $5.9 \%$ ha consumido varios tipos de drogas (entre 3 y 7) de modo frecuente en los últimos 12 meses, seguido de un $22.6 \%$ que ha consumido uno o dos tipos de drogas. Estrechamente relacionado con el consumo de drogas, es de interés resaltar que un $21.5 \%$ de los adolescentes afirman haber consumido diferentes tipos de drogas sin haber pasado dos horas entre el consumo de una u otra (policonsumo), siendo una tasa preocupante para el 3.4\% por su alta ocurrencia.

Los datos ponen de relieve que el $48.8 \%$ de los adolescentes han realizado alguno de los tipos de conductas de riesgo social propuestas, tales como: participar en alguna pelea o agresión física; tener un conflicto o discusión importante con padres o hermanos o ser expulsado del centro educativo durante un día completo o más, de entre los cua- les, un $7.7 \%$ ha realizado mas de 3 de estas conductas, lo que les confiere un carácter alto o muy alto de riesgo social.

Por último, se aprecia que el 19.5\% de los sujetos está directamente implicado en bullying, encontrando menos agresores $8.8 \% \quad(n=109)$ que víctimas $10.1 \% \quad(n=125)$ y una mínima representación de víctimas-provocadores $0.6 \%$ ( $\mathrm{n}=$ 7).

Análisis de la relación entre V ariables socio-demográficas y Factores de riesgo. Los resultados obtenidos a través de la prueba Chi-cuadrado de Pearson con cada uno de los factores transformados en intervalos (Tasa de Consumo, Tasa de policonsumo y Nivel de Conducta Antisocial) atendiendo a las diferentes variables sociodemográficas y académicas, presentan los siguientes aspectos destacables (véase Tabla 3):

Se aprecia una relación entre Tasa de Consumo y edad. Los resultados apuntan que los sujetos de entre 16 y 18 años son los que mas consumen drogas sin ser un consumo esporádico (el 46.7\%), de éstos, el 40\% manifiestan un consumo alto o muy alto de drogas; les siguen los alumnos de entre $14 \mathrm{y}$ 15 años (29\%) y en último lugar los sujetos de entre 11 y 13 años (13.1\%). Vemos que se confirma que el consumo de drogas aumenta considerablemente con la edad del estudiante $(\mathrm{p}=.000)$. Lo que está en la línea de los informes comentados (DGPNSD, 2009).

Además, el fracaso escolar presenta una variación conjunta con el consumo de drogas, y la tasa de consumo es mayor en los que han repetido curso mas de una vez, $(p=.000)$

Tabla 3. Frecuencia, porcentaje y probabilidad Chi-Cuadrado para Variables socio-demográficas y Tasa de Consumo (valores significativos).

\begin{tabular}{|c|c|c|c|c|c|c|c|}
\hline \multirow[t]{2}{*}{ Variable } & & \multicolumn{6}{|c|}{ Tasa de consumo } \\
\hline & & $\mathrm{No}$ & Moderado & Alto & Muy alto & $\chi^{2}$ & $p$ \\
\hline \multirow[t]{3}{*}{ Intervalos Edad } & $11-13$ & $295(86.8 \%)$ & $42(12.4 \%)$ & $2(0.6 \%)$ & $1(0.1)$ & 103.706 & .000 \\
\hline & $14-15$ & $434(71 \%)$ & $148(24.2 \%)$ & $25(4.1 \%)$ & $4(0.7 \%)$ & & \\
\hline & $16-18$ & $144(53.3 \%)$ & $86(31.9 \%)$ & $31(11.5 \%)$ & $9(3.3 \%)$ & & \\
\hline \multirow[t]{3}{*}{ Fracaso escolar } & Repetido un curso & $208(63.2 \%)$ & $92(28 \%)$ & $24(7.3 \%)$ & $5(1.5 \%)$ & 42.711 & .000 \\
\hline & Repetido dos cursos & $60(56.6 \%)$ & $32(30.2 \%)$ & $10(9.4 \%)$ & $4(3.8 \%)$ & & \\
\hline & No repetidor & $603(76.9 \%)$ & $152(19.4 \%)$ & $24(3.1 \%)$ & $5(0.6 \%)$ & & \\
\hline
\end{tabular}

En cuanto a la relación entre edad y Tasa de policonsumo, los resultados señalan que existe una relación manifiesta y que ésta aumenta con la edad (Véase Tabla 4). Al igual que el consumo, el policonsumo aumenta drásticamente con la edad, así, entre los sujetos de entre 11 y 13 años apenas el $1.5 \%$ presentan policonsumo alto o muy alto; los de entre 14 y 15 un $3.7 \%$, mientras que el $5.1 \%$ de los sujetos de entre 16 y 18 años presenta un policonsumo alto o muy alto. Por lo tanto, al igual que ocurría con la tasa de consumo, observamos que el policonsumo aumenta a medida que aumenta la edad de los adolescentes. En cuanto a la relación entre sexo y tasa de policonsumo, no se aprecian diferencias significativas.
La relación entre fracaso escolar y Tasa de policonsumo resultó estadísticamente significativa. Cabe destacar que entre los sujetos que repiten algún curso el porcentaje de los que presentan policonsumo moderado o muy alto es mayor que entre los no repetidores. Por lo que puede decirse que, al igual que ocurre con los intervalos de consumo, el hecho de haber repetido curso es un factor de riesgo para el policonsumo de sustancias adictivas.

Cabe señalar que no hemos encontrado diferencias entre la procedencia de los estudiantes y la tasa de consumo o de policonsumo. 
Tabla 4. Frecuencia, porcentaje y probabilidad Chi-Cuadrado entre Variables socio-demográficas y Tasa de Policonsumo.

\begin{tabular}{|c|c|c|c|c|c|c|c|}
\hline \multirow[t]{2}{*}{ Variable } & \multicolumn{7}{|c|}{ Tramos de policonsumo } \\
\hline & No & Bajo & Moderado & Alto & Muy alto & $\chi^{2}$ & $p$ \\
\hline ๙ ত్తి11-13 & $298(86.4 \%)$ & $18(5.2 \%)$ & $24(7 \%)$ & $2(0.6 \%)$ & $3(0.9 \%)$ & 47.761 & .000 \\
\hline E I I14-15 & $485(79.1 \%)$ & $45(7.3 \%)$ & $60(9.8 \%)$ & $7(1.1 \%)$ & $16(2.6 \%)$ & & \\
\hline E & $183(67 \%)$ & $17(6.2 \%)$ & $59(21.6 \%)$ & $3(1.1 \%)$ & $11(4 \%)$ & & \\
\hline$\circ$ Repetidor un curso & $229(68.8 \%)$ & $26(7.8 \%)$ & $59(17.7 \%)$ & $5(1.5 \%)$ & $14(4.2 \%)$ & 60.445 & .0000 \\
\hline త్ర $\overparen{\Im}$ Repetidor dos cursos & $68(63 \%)$ & $11(10.2 \%)$ & $19(17.6 \%)$ & $3(2.8 \%)$ & $7(6.5 \%)$ & & \\
\hline 胥 & $667(84.6 \%)$ & $43(5.5 \%)$ & $65(8.2 \%)$ & $4(.5 \%)$ & $9(1.1 \%)$ & & \\
\hline
\end{tabular}

Análisis de la relación entre Variables socio-demográficas y Conducta Antisocial (CAS). Como puede observarse en la Tabla 5, han resultado significativas algunas relaciones entre variables, así, resulta estadísticamente significativa la relación entre $C A S$ y edad y, además se aprecia un incremento conforme aumenta la edad de los sujetos (Becoña, 2000). Lo que apunta que los estudiantes de entre 16 y 18 años exhiben más conductas antisociales que los de menor edad. También se aprecian diferencias estadísticamente significativas cuando se relacionan $C A S$ y fracaso escolar, lo que sugiere que, el ser repetidor de curso puede asociarse a presentar conductas predelictivas.

Es de interés resaltar la asociación estadísticamente significativa entre tasa de consumo y CAS. En torno al 53\% de los sujetos presenta junto a una tasa de consumo entre moderada y muy alta, conductas de carácter antisocial. Lo que sugiere que el consumo de drogas está estrechamente asociado a la realización de conductas de carácter antisocial (Farrington, 2005).

Del mismo modo se aprecia una asociación estadísticamente significativa entre policonsumo y $C A S$. De hecho, más del $80 \%$ de los sujetos que consumen varias sustancias sin que haya transcurrido al menos dos horas entre una y otra, dicen realizar varias conductas (entre 4 y 7 ) de carácter antisocial. Estos datos ponen de manifiesto la asociación existente entre el policonsumo de sustancias adictivas y la implicación en determinadas conductas antisociales o de riesgo social.

Tabla 5. Frecuencia, porcentaje y probabilidad Chi-Cuadrado entre Variables socio-demográficas y tramos de conducta antisocial CAS. Variable

Tramos de conducta antisocial

\begin{tabular}{|c|c|c|c|c|c|c|}
\hline & No & Moderado & Alto & Muy alto & $\chi^{2}$ & $p$ \\
\hline$\frac{11}{\sigma} \quad 113$ & $190(63.8 \%)$ & $93(31.2 \%)$ & $12(4 \%)$ & $3(1 \%)$ & 37.464 & .000 \\
\hline 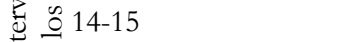 & $259(50.8 \%)$ & $214(42 \%)$ & $33(6.5 \%)$ & $4(0.8 \%)$ & & \\
\hline $16-18$ & $78(37 \%)$ & $110(52.1 \%)$ & $19(9 \%)$ & $4(1.9 \%)$ & & \\
\hline$\exists$ Repetidor un curso & $105(40.5 \%)$ & $127(49 \%)$ & $21(8.1 \%)$ & $6(2.3 \%)$ & 45.413 & .000 \\
\hline đ్ & $32(37.6 \%)$ & $38(44.7 \%)$ & $12(14.1 \%)$ & $3(3.5 \%)$ & & \\
\hline I & $338(57.7 \%)$ & $252(37.4 \%)$ & $31(4.6 \%)$ & $2(0.3 \%)$ & & \\
\hline ○ No & $460(61.5 \%)$ & $270(36.1 \%)$ & $18(2.4 \%)$ & 0 & 242.400 & .000 \\
\hline$\underset{\sigma}{\Xi} \Xi$ Moderada & $60(28.8 \%)$ & $117(56.3 \%)$ & $26(12.5 \%)$ & $5(2.4 \%)$ & & \\
\hline 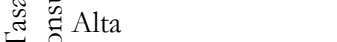 & $3(7 \%)$ & $20(46.5 \%)$ & $15(34.9 \%)$ & $5(11.6 \%)$ & & \\
\hline 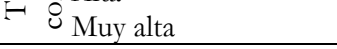 & $1(11.1 \%)$ & $3(33.3 \%)$ & $4(44.4 \%)$ & $1(11.1 \%)$ & & \\
\hline 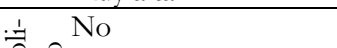 & $488(59.3 \%)$ & $307(37.3 \%)$ & $27(3.3 \%)$ & $1(0.1 \%)$ & 211.000 & .000 \\
\hline$\stackrel{\circ}{\curvearrowright}$ Вајо & $15(27.3 \%)$ & $31(56.4 \%)$ & $8(14.5 \%)$ & $1(1.8 \%)$ & & \\
\hline ช & $19(17.8 \%)$ & $63(58.9 \%)$ & $21(19.6 \%)$ & $4(3.7 \%)$ & & \\
\hline జु & $1(14.3 \%)$ & $3(42.9 \%)$ & $2(28.6 \%)$ & $1(14.3 \%)$ & & \\
\hline$F \quad$ Muy alto & $2(8.3 \%)$ & $12(50 \%)$ & $6(25 \%)$ & $4(16.7 \%)$ & & \\
\hline
\end{tabular}

Relación entre implicación en bullying, variables sociodemográficas, consumo y $C A S$. En primer lugar, analizamos la relación existente entre los roles en bullying y las variables sociodemográficas y académicas mediante la prueba Chi-cuadrado (Véase Tabla 6) y en segundo lugar, las relaciones entre los roles en bullying y la realización de determinadas conductas o acciones de riesgo social y para la salud a través del análisis de varianza, con la prueba post hoc para comprobar el sentido de las diferencias (Véase Tabla 7).

$\mathrm{El}$ análisis de frecuencias apunta que existen diferencias estadísticamente significativas entre el sexo y rol asociado al bullying. Podemos observar que en los roles directamente implicados aparecen más hombres $(n=184)$ que mujeres $(\mathrm{n}=57)$, tanto como agresores como en el rol de víctima, en ambos casos superando la proporción de 3 a 1. El análisis de varianza confirma el sentido de estas diferencias, resultando significativas $(\mathrm{p}=.000)$, quedando por tanto refrendado que los varones están mas implicados en bullying que las mujeres (Cerezo y Ato, 2010).

En cuanto a bullying y fracaso escolar podemos observar que aparecen más agresores que víctimas entre los que han repetido un curso: $12.2 \%(\mathrm{n}=41)$ y también entre los que han repetido dos cursos o más: $16.5 \%(n=18)$. Las comparaciones dos a dos, mediante el análisis de varianza con prueba post hoc, indican que hay mas fracaso escolar entre los agresores que entre los neutros $(p=.002)$ y asimismo es mas probable que hayan repetido curso los agresores que las víctimas $(p=.035)$. 
Tabla 6. Distribución de la muestra global en función de la problemática bullying.

\begin{tabular}{|c|c|c|c|c|c|c|c|}
\hline \multirow[t]{2}{*}{ Variable } & & \multicolumn{6}{|c|}{ Rol asociado } \\
\hline & & Neutro & Agresor & Víctima & Víctima-provocador & $\chi^{2}$ & $p$ \\
\hline \multirow[t]{2}{*}{ Sexo } & Hombre & $428(42.9 \%)$ & $87(79.8 \%)$ & $93(74.4 \%)$ & $4(57.1 \%)$ & 88.708 & .000 \\
\hline & Mujer & $570(57.1 \%)$ & $22(20.2 \%)$ & $32(25.6 \%)$ & $3(42.9 \%)$ & & \\
\hline \multirow[t]{3}{*}{ Fracaso escolar } & Repetidor un curso & $258(25.9 \%)$ & $41(37.6 \%)$ & $34(27.2 \%)$ & $3(42.9 \%)$ & 21.665 & .001 \\
\hline & Repetidor dos cursos & $83(8.3 \%)$ & $18(16.5 \%)$ & $7(5.6 \%)$ & $1(14.3 \%)$ & & \\
\hline & No repetidor & $655(65.8 \%)$ & $50(45.9 \%)$ & $84(67.2 \%)$ & $3(42.9 \%)$ & & \\
\hline \multirow[t]{4}{*}{ Tasa de consumo } & No & $711(72.2 \%)$ & $55(51.9 \%)$ & $105(85.4 \%)$ & $2(28.6 \%)$ & 45.698 & .000 \\
\hline & Moderado & $222(22.5 \%)$ & $38(35.8 \%)$ & $13(10.6 \%)$ & $3(42.9 \%)$ & & \\
\hline & Alto & $41(4.2 \%)$ & $11(10.4 \%)$ & $4(3.3 \%)$ & $2(28.6 \%)$ & & \\
\hline & Muy alto & $11(1.1 \%)$ & $2(1.9 \%)$ & $1(0.8 \%)$ & 0 & & \\
\hline \multirow[t]{5}{*}{ Tasa de Policonsumo } & No & $801(80.7 \%)$ & $56(51.9 \%)$ & $106(86.2 \%)$ & $3(42.9 \%)$ & 119.559 & .000 \\
\hline & Вајо & $53(5.3 \%)$ & $18(16.7 \%)$ & $7(5.7 \%)$ & $2(28.6 \%)$ & & \\
\hline & Moderado & $107(10.8 \%)$ & $27(25 \%)$ & $9(7.3 \%)$ & 0 & & \\
\hline & Alto & $8(0.8 \%)$ & $1(0.9 \%)$ & $1(0.8 \%)$ & $2(28.6 \%)$ & & \\
\hline & Muy alto & $24(2.4 \%)$ & $6(5.6 \%)$ & 0 & 0 & & \\
\hline \multirow{4}{*}{$\begin{array}{l}\text { Indice de conducta antisocial } \\
\text { (CAS) }\end{array}$} & No & $454(54.9 \%)$ & $25(29.8 \%)$ & $48(46.6 \%)$ & 0 & 51.809 & .000 \\
\hline & Moderado & $321(38.8 \%)$ & $42(50 \%)$ & $51(49.5 \%)$ & $3(60 \%)$ & & \\
\hline & Alto & $45(5.4 \%)$ & $13(15.5 \%)$ & $4(3.9 \%)$ & $2(40 \%)$ & & \\
\hline & Muy alto & $7(0.8 \%)$ & $4(4.8 \%)$ & 0 & 0 & & \\
\hline
\end{tabular}

En cuanto a la relación entre bullying y tasa de consumo, la prueba Chi-Cuadrado, pone de manifiesto una asociación estadísticamente significativa. Observamos que aparecen más agresores consumidores que víctimas, tanto en grado moderado como alto o muy alto. El análisis de diferencias a través del Anova, informa que los agresores son los más consumidores cuando se comparan con el resto de subgrupos $(\mathrm{p}=.000)$, y que tanto los sujetos neutros como las víctimas consumen menos que los sujetos víctimas-provocadores, $(\mathrm{p}=.031) ;(\mathrm{p}=.005)$.

En cuanto a la tasa de policonsumo y su relación con el bullying, se puede apreciar que, en cada nivel de policonsumo aparecen más agresores que victimas, y de hecho el único caso de policonsumo muy alto corresponde a un agresor. Podemos decir que los agresores presentan índices más altos en policonsumo a diferencia de las víctimas y los victimasprovocadores. Los análisis de Anova arrojan una diferencia significativa cuando se comparan a los agresores con neutros $(\mathrm{p}=.000)$ y con víctimas $(\mathrm{p}=.000)$.
En cuanto a la relación entre nivel de conductas antisociales (CAS) y bullying, encontramos que los víctimas superan a los agresores cuando se trata de un nivel de CAS moderado: $12.2 \%$ frente a $10.1 \%$, seguidos de los víctimasprovocadores $(.7 \%)$; sin embargo cuando el índice es alto aparecen más agresores $(20.3 \%)$ que víctimas $(6.3 \%)$ y que victimas-provocadores (3.1\%); finalmente, en el índice muy alto, solo aparecen agresores $(36.4 \%)$, por tanto a mayor nivel de conducta antisocial mayor es la asociación con conductas agresivas. Los análisis Anova confirman que, al comparar neutros y agresores, destacan los agresores $(p=.000)$, al igual que entre agresores y víctimas $(\mathrm{p}=.000$ ) (Cerezo y Méndez, 2009; Farrington y Ttofi, 2011). Del mismo modo, al comparar los víctimas-provocadores con los neutros, son aquellos los que destacan ( $\mathrm{p}=.016)$, así como al compararlos con los víctimas $(\mathrm{p}=.033)$. Por lo que podemos afirmar que todos los sujetos que presentan algún tipo de conducta agresiva en el entorno escolar realizan conductas antisociales en mayor medida que los no agresores.

Tabla 7. Diferencias significativas entre roles en bullying y factores de riesgo.

\begin{tabular}{|c|c|c|c|}
\hline Variables & Roles asociados al bullying & & \\
\hline & $F$ & Diferencias de medias & $p$ \\
\hline \multirow[t]{2}{*}{ Sexo } & $\overline{F(3 ; 1235)=31.747, p=.000}$ & Neutro-Agresor $=.369$ & .000 \\
\hline & & Neutro-Víctima=.315 & .000 \\
\hline \multirow[t]{2}{*}{ Fracaso escolar } & Brown-Forsythe & Neutro-Agresor=.316 & .002 \\
\hline & $F(3 ; 1233)=4.715, p=.003$ & Agresor-Víctima = -.317 & .035 \\
\hline \multirow[t]{4}{*}{ Tasa consumo } & $\mathrm{F}(3 ; 1217)=12.026, \mathrm{p}=.000$ & Neutro-Agresor $=-.281$ & .000 \\
\hline & & Neutro-Vict. provocador $=-.658$ & 031 \\
\hline & & Agresor-Victima $=.428$ & .000 \\
\hline & & Víctima-Víct. provocador $=-.805$ & .005 \\
\hline \multirow[t]{2}{*}{ Tasa Policonsumo } & $\mathrm{F}(3 ; 1227)=14.872, \mathrm{p}=.000$ & Neutro-Agresor $=-.26347$ & .000 \\
\hline & & Agresor-Victima=.34451 & .000 \\
\hline \multirow[t]{4}{*}{ Índice de CAS } & Brown-Forsythe & Neutro-Agresor $=-.430$ & .000 \\
\hline & $\mathrm{F}(3 ; 1015)=13.957, \mathrm{p}=.000$ & Neutro-Vict.-provocador $=-.878$ & .016 \\
\hline & & Agresor-Víctima=.380 & .000 \\
\hline & & Víctima-Vict. provocador $=-.827$ & .033 \\
\hline
\end{tabular}




\section{Análisis del grupo-aula}

Prevalencia del bullying en el grupo-aula. Los resultados del Test Bull-S (Cerezo, 2000) ponen de manifiesto la presencia de situaciones de agresión mantenida, detectando, entre los 27 alumnos que conforman el grupo, 2 agresores, 2 víctimas y un víctima-agresor. La valoración de los agresores (sujetos que llamaremos B1 y B2) es la siguiente: el sujeto B1 presenta un nivel de agresividad percibida del $26 \%$, es considerado como el mas fuerte de la clase por el $45 \%$ del grupo, provocador o aquel que empieza las peleas por el $45 \%$ y tiene un grupo de 3 amigos que lo apoya, por otro lado es rechazado por 3 sujetos, entre los que figura una de las víctimas (V1), el nivel de rechazo medio no es significativo. El sujeto B2 presenta un nivel de agresividad percibida de $41 \%$, es considerado el más fuerte del grupo por el 38\% de sus compañeros y como provocador por el $56 \%$. Cuenta con cuatro apoyos dentro del grupo pero a su vez es rechazado por 11 compa- ñeros, entre los que se encuentra el sujeto víctima V1, con una puntuación ponderada de 32 puntos, lo que le sitúa como el alumno mas rechazado del grupo. El resto del grupo de iguales apenas participa en las situaciones de agresión o de protección y tanto el equipo directivo como el profesorado están ajenos a la situación concreta de acoso.

El análisis de las variables situacionales, como puede apreciarse en la Tabla 8, revela que, las formas más habituales de agresión son los insultos y amenazas, seguida por el rechazo y en último lugar la agresión física. Por otra parte, los lugares donde suelen producirse las agresiones, parece que todos son propicios por igual, es decir, el aula, los pasillos, seguido de otros lugares y el patio. La frecuencia con la que ocurren las agresiones es señalada como "rara vez" o "nunca" por el 33.3\% del grupo, mientras que el 37\% afirma que se dan todas las semanas o diariamente.

Tabla 8. Percepción del grupo ante el bullying.

\begin{tabular}{lllll}
\hline Formas & Lugares & Frecuencia & Gravedad & Seguridad \\
\hline Insultos y Amenazas:65.4\% & Aula: $42.3 \%$ & Rara vez: $33.3 \%$ & Regular: $33 \%$ & Mucho: $37 \%$ \\
Rechazo: $26.9 \%$ & Patio: $42.3 \%$ & $1-2$ veces por semana: $63 \%$ & Poco: $26 \%$ & Bastante: $33.3 \%$ \\
Maltrato físico: $7.7 \%$ & Pasillos: $3.8 \%$ & Todos los días: $3.7 . \%$ & Bastante: $26 \%$ & Regular: $26 \%$ \\
Otras formas: $0 \%$ & Otros lugares: $11.5 \%$ & Nunca: $\%$ & Mucho: $14.8 \%$ & Poco: $3.7 \%$ \\
\hline
\end{tabular}

La percepción de gravedad de estas situaciones es muy dispar, se aprecian dos posturas casi antagónicas: así el 59\% del grupo apenas percibe gravedad en ellas, mientras que cerca del $41 \%$ considera que son bastante o muy graves. Por último, la percepción de seguridad en el centro es alta para el $70 \%$ de los sujetos, y por el contrario el 30\% afirma sentirse regular o poco seguro.

Sobre la estructura relacional del grupo-aula cabe destacar que se aprecia un nivel de cohesión medio, lo que se traduce en que el $64.2 \%$ de los alumnos se siente miembro del grupo, mientras que 17 sujetos están aislados y 2 sujetos son muy rechazados, frente a esto, no se aprecia a ningún sujeto líder o muy popular. Por otra parte, los grupos de afinidad son poco extensos.

Prevalencia del consumo de drogas en un grupo-aula. El análisis grupal de la Encuesta a Estudiantes sobre Drogas, véase Tabla 9, reveló que un porcentaje considerable de estudiantes consume con frecuencia algunas drogas, entre las que destacan: tabaco $(22.2 \%)$, bebidas alcohólicas (7.4\%), y tranquilizantes para dormir sin receta médica (18.5\%). El 22.2\% dice haber probado alguna vez el hachís, entre los que destacan aquellos que han repetido curso alguna vez.

Agrupando las variables sobre consumo de drogas en una tasa global encontramos que el 55.6\% no ha consumido ningún tipo de droga en los últimos 12 meses. Mientras que, el $44.4 \%$ ha probado alguna vez alguna de la drogas mencionadas; el $18.5 \%$ (5 casos) consume mas de una de ellas de vez en cuando y el $7.4 \%$ (2 casos) consume mas de una semanalmente y otro tanto lo hace con asiduidad casi diaria. Esto pone de manifiesto que el 45.5\% del grupo tiene algún contacto con las drogas, incluso, uno de ellos reconoce haber tenido problemas por el consumo de cannabis. Además, el 33.3\% reconoce que, al menos una vez, ha consumido bebidas alcohólicas y cannabis sin haber pasado dos horas, lo que se traduce en policonsumo, siendo significativo en el $37 \%$ de los casos. Sin embargo, el nivel de percepción de riesgo es muy bajo en general, solo el $11.1 \%$ considera que estas actividades ponen en riesgo su salud, aunque todos aseguran que el consumo de estas sustancias es malo (Becoña et al., 2011).

Tabla 9. Realización de conductas de riesgo social y para la salud en el grupo

\begin{tabular}{|c|c|c|c|c|c|c|c|}
\hline $\begin{array}{l}\text { Acciones } \\
\mathrm{N}(\%)\end{array}$ & $\begin{array}{l}\text { Fumar cigarrillos } \\
\text { diaria-mente }\end{array}$ & $\begin{array}{l}\text { Beber alcohol } \\
\text { semanal-mente }\end{array}$ & $\begin{array}{l}\text { Consumir hachís } \\
\text { alguna vez }\end{array}$ & $\begin{array}{l}\text { Acciones de riesgo } \\
\text { para la salud }\end{array}$ & $\begin{array}{l}\text { Tasa } \\
\text { Policonsumo }\end{array}$ & $\begin{array}{l}\text { Tasa de } \\
\text { consumo }\end{array}$ & Tasa CAS \\
\hline $\mathrm{Si}$ & $6(22.2 \%)$ & $2(7.4 \%)$ & $6(22.2 \%)$ & $3(11.1 \%)$ & $10(37 \%)$ & $12(44.4 \%)$ & $16(59.3 \%)$ \\
\hline No & $21(77.8 \%)$ & $25(92.6 \%)$ & $21(77.8 \%)$ & $24(88.9 \%)$ & $17(63 \%)$ & $15(55.6 \%)$ & $11(40.7 \%)$ \\
\hline
\end{tabular}

Más de la mitad de los alumnos del grupo han realizado acciones de carácter antisocial o de riesgo, como: viajar bajo los efectos del alcohol como conductor $(7.4 \%)$ o como pasa- jero $(25.9 \%)$; participar en alguna pelea $(14.8 \%)$, tener algún conflicto importante con sus padres o hermanos (40.7\%). Agrupando estas conductas, junto con haber sido detenido 
por las fuerzas de orden público, escaparse de casa durante mas de un día y ser expulsado del centro educativo, nos permite calcular el índice de riesgo social, cuyo valor es relevante para el $11.1 \%$ de la muestra.

Otras acciones relacionadas con la percepción de la convivencia escolar, revelan que, el $81.5 \%$ reconoce no haber tenido problemas de convivencia en los cursos de educación primaria, mientras que el $7.4 \%$ (2 sujetos) dice que sus compañeros se metían con el/ella y sufrió acoso escolar y 1 sujeto reconoce que en ocasiones sufrió acoso y en otras participó como agresor. El conjunto de la muestra reconoce que tiene recuerdos agradables de su etapa de primaria, aunque el $11.1 \%$ (3 sujetos) dicen que no son agradables; 2 sujetos dicen que durante ese curso académico "una o dos veces" ha sufrido maltrato y 3 sujetos afirman haber participado en episodios de maltrato en su centro escolar. Por otra parte, 1 sujeto ha faltado a clase porque "no tuvo ganas de asistir" y, en la misma proporción, se ha escapado de casa durante más de un día.

Factores de riesgo interpersonal en el grupo aula. El análisis del test Frida, cuyos datos significativos se pueden apreciar en la Tabla 10, puso de manifiesto que el acceso a las drogas resulta claramente fácil para el $11.1 \%$ del grupo y relativamen- te fácil para el $66.7 \%$, mientras que solo le sería difícil al $22.2 \%$ restante, por tanto, se confirma que el acceso a las drogas es relativamente fácil para los adolescentes.

El factor de vulnerabilidad global se sitúa en niveles bajos para la mayoría de los sujetos $(88.9 \%)$, mientras que para el resto (3 casos) resulta de valor medio, lo que indica que para la mayoría del grupo el ambiente familiar y de amigos no facilita mucho el desarrollo de conductas de riesgo (Cava, Murgui y Musitu, 2008). Analizando cada uno de los factores que componen este valor global, encontramos algunos factores significativos, así, el nivel de reacción familiar ante el consumo es bajo para el $37.1 \%$ del grupo, lo que indica que padres y adultos en general, se enfadarían poco o nada si los pillasen bebiendo o fumando. El factor reacción de los amigos es igualmente bajo para el 63\%, lo que implica que para éstos, sus amigos son consumidores, tienen actitudes positivas hacia el consumo de drogas y con frecuencia realizan actividades de riesgo (Inglés et al., 2007; Sánchez et al., 2007). El factor riesgo familiar es alto o medio para el $18.5 \%$ lo que indica que, en estos casos, las relaciones son poco afectuosas, el sujeto se siente maltratado, percibe un alto nivel de conflicto en el seno familiar y los familiares consumen algún tipo de droga (Ruiz-Juan y Ruiz-Risueño, 2011).

\begin{tabular}{lllllllll}
\multicolumn{2}{l}{ Tabla 10. Factores de riesgo personal y social en el grupo-aula } \\
\hline $\begin{array}{l}\text { Valor } \\
\%\end{array}$ & $\begin{array}{l}\text { Reacción } \\
\text { familia }\end{array}$ & $\begin{array}{l}\text { Grupo } \\
\text { amigos }\end{array}$ & $\begin{array}{l}\text { Facilidad } \\
\text { acceso }\end{array}$ & $\begin{array}{l}\text { Riesgo } \\
\text { familiar }\end{array}$ & $\begin{array}{l}\text { Educación } \\
\text { Familiar }\end{array}$ & $\begin{array}{l}\text { Actividades } \\
\text { Protectoras }\end{array}$ & $\begin{array}{l}\text { Control } \\
\text { Familiar }\end{array}$ & $\begin{array}{l}\text { Riesgo } \\
\text { global }\end{array}$ \\
\hline Bajo & $44.4 \%$ & - & $22.2 \%$ & $14.8 \%$ & $22.2 \%$ & $44.4 \%$ & $3.7 \%$ & $88.9 \%$ \\
Medio & $18.5 \%$ & $37.0 \%$ & $66.7 \%$ & $3.7 \%$ & $48.1 \%$ & $33.3 \%$ & $14.8 \%$ & $11.1 \%$ \\
Alto & $37.0 \%$ & $63.0 \%$ & $11.1 \%$ & $81.5 \%$ & $25.9 \%$ & $22.2 \%$ & $77.8 \%$ & - \\
\hline
\end{tabular}

Nota. Los datos se refieren a los registrados y no se recogen los perdidos por el sistema.

El $25.9 \%$ del grupo dice que no ha recibido una educación familiar o escolar sobre drogas, lo que implica que el nivel de información es moderado o alto para una mayoría de los sujetos, y a su vez una amplia mayoría percibe que sus padres imponen normas estrictas.

En cuanto al factor denominado actividades de protección, como hacer deporte u otras actividades culturales con asiduidad, mantener buenas relaciones familiares y con amigos y tener éxito escolar, es escaso en el $44.4 \%$ de los casos. Lo que indica que casi la mitad de los sujetos se encuentran bastante alejados de actividades que puedan suponer una protección ante el uso de drogas y otras acciones de riesgo.

En cuanto al control familiar o estilo educativo, los datos reflejan que un caso apreciaba un estilo democrático, el $14.8 \%$ apreciaba un estilo moderado y la gran mayoría
(80.8\%) consideraba que respira un ambiente familiar permisivo.

Otro dato que nos parece relevante es que entre los elementos que configuran el factor relaciones familiares el $11.1 \%$ afirmaba llevarse bastante mal o muy mal con su padre y el $3.7 \%$ con su madre.

Análisis comparativo según el rol en bullying y los factores de riesgo. En el grupo se aprecia: Neutro o no implicado (22 casos), agresor ( 2 casos), víctima (2 casos) y víctima-agresor (1 caso). Las diferencias mas sobresalientes entre estos subgrupos pueden verse en la Tabla 11 donde se muestran únicamente las respuestas positivas dadas por los sujetos a cada una de las preguntas.

Tabla 11. Contingencia por roles en bullying y factores de riesgo en el grupo-aula.

\begin{tabular}{|c|c|c|c|c|c|c|c|}
\hline Rol en Bullying & $\begin{array}{l}\text { Tasa } \\
\text { consumo }\end{array}$ & Policonsumo & Fácil acceso & $\begin{array}{l}\text { Riesgo Social } \\
\text { Medio }\end{array}$ & $\begin{array}{l}\text { Riesgo } \\
\text { familiar }\end{array}$ & $\begin{array}{l}\text { Estilo educativo } \\
\text { Permisivo }\end{array}$ & $\begin{array}{l}\text { Buenas Relaciones } \\
\text { con Padre/Madre }\end{array}$ \\
\hline Neutro & $35.3 \%$ & $13.6 \%$ & $72.7 \%$ & $50 \%$ & $77.3 \%$ & $85.7 \%$ & $81.8 \% / 95.2 \%$ \\
\hline Agresor & $50 \%$ & $50 \%$ & $100 \%$ & $100 \%$ & $100 \%$ & - & $50 \% / 100 \%$ \\
\hline Víctima & - & $50 \%$ & $100 \%$ & $100 \%$ & $100 \%$ & $100 \%$ & $100 \% / 100 \%$ \\
\hline Víctima-Provocador & $100 \%$ & $100 \%$ & $100 \%$ & - & $100 \%$ & $100 \%$ & $100 \% / 100 \%$ \\
\hline
\end{tabular}

* En cursiva los valores referidos a las madres 
En primer lugar, destaca la mayor tasa de consumo, generalmente de alcohol y tabaco, en aquellos sujetos que están implicados en bullying, llegando al policonsumo ocasional en la mayoría de los casos. En el conjunto del grupo, destaca la facilidad para el acceso a las drogas y especialmente entre los implicados, que aseguran que no les supondría ningún problema conseguir los diferentes tipos de droga sugeridos. El conjunto de las variables relacionadas con la realización de actividades de riesgo social no es alto para ninguno de los subgrupos, sin embargo, se observa que alcanza niveles medios para la totalidad de los estudiantes agresores y víctimas.

Aspectos de las relaciones familiares nos sugieren diferencias entre los sujetos, así, para todos los implicados en bullying destaca que éstas son poco afectuosas o existe maltrato, que los familiares son consumidores de drogas y se aprecian situaciones de elevado conflicto familiar. En cuanto al estilo educativo familiar, es apreciable que tanto los sujetos víctimas como el víctima-agresor, perciben un ambiente permisivo, mientras que los agresores lo perciben moderadamente democrático (Cerezo, 2009b). Por último, destacar que $50 \%$ de los agresores percibe una relación negativa con el padre (Torrente y Rodríguez, 2004).

\section{Análisis del caso B2}

Proponemos el análisis del sujeto que hemos denominado B2 por tratarse del caso con un índice de agresividad apreciable y por encontrarse en una situación de vulnerabilidad dada su implicación en otras conductas de riesgo social y para su bienestar.

Descripción del caso. Se trata de una chica de 16 años, repetidora (un curso). Tiene un pequeño grupo de amigos (4 compañeros), todos repetidores, como ella. Considera que las agresiones ocurren fuera del recinto escolar una o dos veces por semana, que son bastante graves y ella se encuentra solo regular de segura en el centro. Por otra parte es percibida como provocadora por el $56 \%$; agresiva por el $41 \%$; las más fuerte del grupo por el 38\%; le tiene manía el 15\% y es considerada cobarde por el $12 \%$. Es rechazada por 11 compañeros, con una puntuación ponderada de 32 puntos, lo que la sitúa como el sujeto mas rechazado del grupo, aspecto que ella misma observa, ya que presenta una expectativa de rechazo significativa. Este punto permite suponer que estamos ante un caso de agresividad reactiva motivado por las consecuencias de dicho rechazo.

Características de riesgo asociadas. En cuanto al consumo de sustancias tóxicas, afirmó que fuma diariamente, toma bebidas alcohólicas frecuentemente (1-2 días a la semana), en ocasiones se emborrachaba, con un promedio de 1-2 veces en los últimos 12 meses. Ha tomado hachís o marihuana alguna vez y en un par de ocasiones tuvo problemas por su consumo. Reconoce que toma alcohol y otras sustancias en menos de dos horas (entre 3-9 veces). Como resumen, la ta- sa de consumo de drogas es alta, además dice que le resulta muy fácil conseguir las drogas.

Se aprecian situaciones de riesgo social global, entre las que destacan: reconocer haber tenido problemas de convivencia escolar, aunque considera que no son actividades de riesgo; haber faltado clase en los últimos 30 días por "no tener ganas de ir" y haber participado en peleas (como actor o como receptor) 1 o 2 veces en los últimos 12 meses. Junto a esto realiza actividades protectoras de manera moderada como hacer deporte con asiduidad.

En cuanto a factores de riesgo familiar y del grupo de amigos en relación al consumo, siguiendo los baremos propuestos en el test Frida (véase el perfil del sujeto B2 en la Tabla 12) podemos destacar que la reacción de la familia ante el consumo es un factor de alto riesgo para el consumo del sujeto (PT: 15) al que cabe añadir la percepción de situaciones de maltrato ocasionado por sus padres y otros familiares, aunque apunta que se preocupan por ella y la quieren. En ocasiones, percibe que sus padres discuten y esto le preocupa mucho y le altera igualmente. Las relaciones con sus padres son dispares, así dice llevarse muy mal con el padre y muy bien con la madre. Por otro lado, aunque el ambiente familiar no es permisivo con el consumo de tabaco y otras drogas, puesto que tanto la madre como el padre "reaccionarían con mucho enfado si la vieran consumir tabaco o drogas", sin embargo, no lo harán ante el consumo de alcohol. El estilo educativo puede calificarse de intermedio (PT:7) entre democrático y permisivo, quizá sea inconsistente o fluctuante según las situaciones, lo que puede llevar a no tener claras las normas ni los límites.

En cuanto a los factores de riesgo con los amigos, la chica dice que sus amigos fuman bastante o mucho y que beben casi diariamente, e incluso que a veces consumen otro tipo de drogas, junto a esto, considera que consumir drogas es malo. El valor promedio de la reacción de los amigos ante el consumo es medio-alto (PT: 13), por lo que cabe pensar que sus amigos son consumidores, tienen actitudes positivas hacia las drogas y que con frecuencia, realiza actividades de riesgo con ellos, lo que puede favorecer que mantenga la conducta de consumo.

$\mathrm{El}$ promedio de los factores de riesgo arroja un índice de vulnerabilidad global con una puntuación típica de 13 , lo que indica un valor alto, por tanto, la familia y el grupo de amigos, núcleos afectivos y sociales de la joven, presentan altos índices de riesgo para el consumo.

Tabla 12. Perfil obtenido en el Test Frida del sujeto B2

\begin{tabular}{ll}
\hline Factores & PT \\
\hline 1. Reacción de la familia ante el consumo & 15 \\
2. Grupo de amigos & 13 \\
3.Acceso a las drogas & 15 \\
4. Riesgo familiar & 11 \\
5.Educación familiar en drogas & 6 \\
6. Actividades protectoras & 13 \\
7.Estilo educativo & 7 \\
Indice de Vulnerabilidad Global & 14 \\
\hline
\end{tabular}


Grado de inadaptación. El resultado global del cuestionario TAMAI indica que el grado de Inadaptación general (PD: 31) es casi bajo, lo que da a entender que esta chica muestra escasa capacidad para acoplarse y estar a gusto consigo misma y con el ambiente en el que tiene que vivir, por lo que será previsible que se encuentre involucrada en situaciones conflictivas o problemáticas importantes (Lösel y Bender, 2011). Esta apreciación global se descompone en cuatro factores: personal, escolar, social y familiar. El bajo valor encontrado en Inadaptación Personal (PD: 10) es un indicativo de que puede tener algunas dificultades consigo misma (autoajuste) ya que, aunque se valora suficientemente y no experimenta sentimientos de culpabilidad, y se aprecian elementos depresivos como sentimientos de tristeza (Cerezo, 2001).

En cuanto al factor escolar, con una puntuación de 14 puntos, indica una inadaptación escolar baja, donde confluyen por un lado, la escasa satisfacción con su propio comportamiento académico y la actitud poco favorable hacia los profesores, de hecho señala que está a disgusto con los profesores que tiene, que cree que es bastante vaga y suele molestar en clase; y hacia la propia institución ya que reconoce que está deseando que se acaben las clases para marcharse, se hace preciso señalar que ha repetido curso. Estos datos se ven refrendados con sus respuestas en el Test Bull-S donde dice que las situaciones de agresión son bastantes graves y que solo se encuentra regular de segura en el centro educativo. En la escala de Inadaptación Social obtiene una puntuación baja (PD: 7), lo que significa que muestra una relativa consideración hacia los demás y a las normas establecidas, aunque reconoce que se enfada, discute y se pelea con facilidad y que tiene mal genio, los demás suelen decir de ella que es inquieta y revoltosa, lo que indica que existe discrepancia entre lo que dice de si misma y lo que cree que dicen los otros. Esto nos puede indicar que su comportamiento se relaciona con una interpretación cognitiva negativa sobre los sentimientos que despierta en los demás y por tanto tiene un fuerte carácter reactivo.

La escala de Insatisfacción con el ambiente Familiar, presenta un valor casi-bajo (PD: 25), si descomponemos dicho factor encontramos que por una parte la insatisfacción con el padre es media (PD: 43) y la insatisfacción con la madre es baja (PD: 7), esto confirma que su relación con la madre es buena pero no así con el padre. Esto nos lleva a destacar que existe una Discrepancia educativa padre/madre alta (PD:88), lo que indica que la percepción del comportamiento de los progenitores hacia ella es muy dispar, así por una parte, siente que la madre la quiere, protege y se preocupa por ella, es cercana y comprensiva pero a la vez está pendiente y la castiga cuando es necesario, mientras que su padre es distante, poco comunicativo, poco considerado con ella y siempre le está llamando la atención, controlando todo lo que hace y se siente muchas veces abandonada. La alta discrepancia entre los comportamientos de ambos progenitores, indica que existe una problemática que puede ser origen de distintas inadaptaciones.
Como resumen del análisis, podemos decir que estamos ante una chica que se relaciona exclusivamente con compañeros que son repetidores con los que mantiene una estrecha relación de amistad, entre los que destacan actitudes favorables al consumo y a las actividades de riesgo social y para la salud. El ambiente escolar no le satisface y tampoco el familiar donde encuentra serios problemas de adaptación, especialmente con su padre.

\section{Propuesta de programa de intervención en un caso de bullying}

En el camino para resolver las problemáticas detectadas, se hace imprescindible la educación y concienciación en los jóvenes. Será función del docente concienciar y transmitir información acerca de las mismas, al mismo tiempo que educar y proporcionar valores y actitudes que favorezcan una vida saludable. Hemos de tener en cuenta que, el problema del consumo abusivo de sustancias posee un origen multicausal (Inglés, et. al. 2007), siendo por lo tanto imprescindible múltiples acciones preventivas, orientadas a los múltiples escenarios. Desde los resultados del análisis del grupo proponemos una serie de estrategias para la intervención contextualizada. La propuesta, basada en el programa CIP (Cerezo et al., 2011), está orientada no solo al sujeto agresor, sino al grupo aula en su conjunto e involucrando al profesor tutor, al orientador educativo y a la familia. Siguiendo la estructura en seis fases sucesivas, que se establecen a continuación.

1. Planteamiento del problema: Concienciación sobre las consecuencias del consumo de drogas y la problemática bullying. Tanto con profesores y alumnos como con padres.

Elaboramos una serie de cuestiones que serán debatidas, tales como:

- Piensa en el problema del consumo y de bullying en "tu" escuela. ¿Qué tipo de conductas crees que lo favorecen?. Por ejemplo: los profesores dicen que eso son "chismes"; el escaso número de supervisores en los espacios comunes, etc. Haz una lista de todas las cosas que pienses que pueden favorecerlo.

¿Cómo te afecta esta problemática?. Algunos alumnos que tienen miedo de contarlo por lo que pueda ocurrirles. ¿Cómo podríamos hacerlo visible?

¿Qué señales pueden alertar a padres, profesores y compañeros?.

¿Qué se puede hacer desde la escuela y desde la familia para ayudar a los implicados?. ¿Qué pueden hacer los alumnos, que pueden hacer los profesores y qué pueden hacer los padres?

Sensibilización ante el consumo de sustancias adictivas y ante otras conductas de riesgo social y para la salud. Tratar de encontrar fórmulas de cambio. ¿Qué podrían hacer los profesores, los alumnos y demás personal para prevenir el consumo? 
2. Análisis de la situación. Una vez establecida la demanda de actuación, se procede a la evaluación precisa del alcance del problema. Los resultados globales son comunicados al centro educativo para que puedan tomarse medidas. Se debaten y aclaran.

3. Intervención especifica. Se plantea el abordaje terapéutico con la chica B2. La intervención abarcará tres aspectos principalmente: la situación de rechazo y bullying; las conductas de riesgo para la salud y social, y las relaciones interpersonales con los padres. Los puntos a trabajar versarán sobre:

- Motivar para el cambio.

- Enseñanza de conductas de control y comportamientos alternativos.

- La importancia de los amigos. Analizar y aplicar estrategias de afrontamiento.

- Las relaciones familiares. Cómo mejorar las relaciones.

- Entrenamiento en control cognitivo del pensamiento.

- Control de cambios y adopción de nuevas conductas a través de un contrato de supervisión y sanción.

4. Intervención con un grupo-aula. Se plantea como parte de la acción tutorial y abarca los siguientes aspectos:

- Trabajar técnicas de afrontamiento y de respuesta asertiva.

- Potenciar el Trabajo en Grupo y el Trabajo Cooperativo. - Desarrollo de Actividades Lúdicas.

5. La intervención con las familias. Se estructura en torno a un plan para afrontar el cambio que favorezca la implicación de los padres y en especial del padre del sujeto B2, en la prevención de conductas de riesgo.

6. Seguimiento. Se establece que el programa deberá supervisarse cada 15 días durante la fase de aplicación.

Como ventajas de la aplicación de esta propuesta de intervención en y con el propio centro educativo destacamos el planteamiento ecológico global que incluye la implicación del equipo directivo y del personal docente junto a las familias en la prevención e intervención ante los riesgos que presentan los jóvenes, al mismo tiempo, son los propios alumnos los que elaboran sus propuestas concretas, lo que servirá para garantizar la integración efectiva de los alumnos aislados y rechazados y prevenir del consumo de drogas y de otras conductas de riesgo social y para la salud. Finalmente, destacamos la necesidad de colaboración entre instituciones sociales, sanitarias y educativas, ya que es fundamental su papel en la detección precoz sobre todo en alumnos en situación de riesgo.

\section{Conclusiones}

Los datos de este estudio confirman que la adolescencia es una etapa del ciclo vital de especial vulnerabilidad donde el individuo puede mostrar un amplio abanico de conductas de riesgo social, llegando incluso a quebrantar las normas sociales de convivencia atentando contra los derechos de los demás (Farrington, 2005), pero también de riesgo para su propia salud (Cerezo y Méndez, 2009; Farrington y Ttofi, 2011). En primer lugar, destaca el riesgo de consumo de sustancias adictivas, siendo una conducta bastante extendida, si tenemos en cuenta que, un considerable porcentaje de sujetos presentan un patrón de consumo habitual de estas sustancias $(28.5 \%)$ e incluso un $21.5 \%$ ha llevado a cabo policonsumo, es decir, han consumido diferentes tipos de drogas sin haber pasado dos horas entre el consumo de una u otra. La tasa de consumo de drogas legales (tabaco y alcohol) es equivalente entre chicos y chicas, sin embargo los chicos destacan en el consumo de otro tipo de sustancias.

La edad se conforma como un factor de riesgo, así ocurre que a mayor edad, mayor es el consumo y por tanto mayor riesgo para la salud (Ruiz-Juan y Ruiz-Risueño, 2011; Sánchez, Moreno, Muñoz y Pérez, 2007), pero no solo en cuanto al consumo, esta relación también es relevante para las conductas antisociales e incluso con la probabilidad de ser agresor en bullying. Esta gama de conductas se presentan asociadas, de manera que nos permite concluir que las conductas de riesgo social y para la salud, además de estar bastante extendidas entre los adolescentes, se asociadan a conductas de carácter antisocial (Estevez y Emler, 2011; Pérez y Gázquez, 2010).

En cuanto al nivel de incidencia del bullying encontrado en este estudio resulta semejante a los observados en otras ocasiones, lo que supone que el fenómeno del maltrato entre iguales está estabilizado (Cerezo, 2009a). Del mismo modo, se aprecia que la mayoría de los implicados en esta dinámica son varones (Aviles y Monjas, 2005; Cerezo y Ato, 2010).

En cuanto a la relación entre bullying y conductas de riesgo para la salud, nuestro estudio confirma que los agresores son mas consumidores de drogas de modo habitual y que incluso llevan a cabo el policonsumo frente a los victimas y victimas-provocadores (Renda, Vassallo y Edwards, 2011). Además se aprecia una estrecha relación entre la implicación en la problemática bullying y la realización de varias conductas antisociales o de riesgo social (Cerezo y Méndez, 2009; Farrington y Ttofi, 2011), así, encontramos una relación significativa entre ser agresor y realizar otras conductas antisociales como participar en alguna pelea, tener conflicto o discusiones importantes con padres o hermanos, lo que vendría a confirmar, como señala Becoña et al., (2011), que los jóvenes consumidores de drogas suelen relacionarse de forma agresiva con los demás. Es de destacar que, todos los sujetos que presentan algún tipo de conducta agresiva en el entorno escolar (agresores y víctimas-provocadores) realizan conductas antisociales en mayor medida que los no agresores.

El estudio pone de relieve que un alto porcentaje de estudiantes que afirman haber repetido curso alguna vez (36\%) han consumido drogas. Así pues, existe una alta relación entre fracaso escolar y consumo de drogas, tal es así que el fracaso escolar se configura como un factor de vulnerabilidad tanto para el consumo como para el policonsumo de sustan- 
cias adictivas, a lo que debe añadirse una alta relación entre estas variables y la realización de conductas de carácter antisocial. Por otra parte, se hace evidente, como ya se ha comentado, que existe una relación significativa entre repetir curso y ser agresores en bullying, lo que nos permite concluir que el fracaso escolar es una condición que se suma a la situación de riesgo social y para la salud en los adolescentes. La procedencia de los sujetos no ha resultado relevante en este estudio.

En cuanto al grupo-aula de $4^{\circ}$ curso de la ESO, apreciamos que el $22.2 \%$ del grupo-aula afirmó haber probado alguna vez el hachís, entre los que destacan aquellos que han repetido curso alguna vez, lo que está en consonancia con los trabajos de Inglés, et. al, (2009) y pone de manifiesto que aquellos estudiantes que son repetidores muestran una tasa de conductas antisociales significativamente mayor que aquellos que no han repetido ningún curso escolar. El análisis del grupo confirma que la cantidad de adolescentes que se encuentran en situación de riesgo para el consumo de drogas así como otras conductas de riesgo social no es anecdótica, lo que plantea la necesidad de considerar prioritario la formación en conductas prosociales (Garaigordobil y Oñederra, 2008).

El estudio del caso presentado, confirma el papel decisivo de los amigos en la asunción de conductas de riesgo. Si tenemos en cuenta que uno de los principales modelos de comportamiento para los adolescentes lo conforma el grupo de iguales, es previsible que, como algunos estudios apuntan, aquellos adolescentes con modelos consumidores tienen una actitud más favorable al consumo de drogas (Alfonso, Huedo-Medina y Espada, 2009; Sánchez, Moreno, Muñoz y Pérez, 2007), ya que el grupo de amigos facilita no solo el acceso a las drogas sino también respalda al sujeto emocionalmente, disminuyendo sus temores ante el consumo. En este sentido resulta especialmente relevante la figura del mejor amigo (Espada, Pereira y García-Fernández, 2008), al que hay que sumar el efecto de los modelos familiares (Ruiz-Juan y Ruiz-Risueño, 2011; Torrente y Rodríguez, 2004). Nuestro estudio permite avanzar que no solamente influyen en conductas de riesgo para la salud sino también de riesgo personal y otras conductas antisociales. El análisis del caso destacado pone en evidencia algunos aspectos del entorno familiar que pueden estar facilitando la asunción de riesgos para la salud, así, el consumo de determinadas sustancias adictivas en el entorno familiar y especialmente el tipo de relación que

\section{Referencias}

Alfonso, J. P., Huedo-Medina, T. B. y Espada, J. P. (2009). Factores de riesgo predictores del patrón de consumo de drogas durante la adolescencia. Anales de Psicología, 25(2) 330- 338

American Psychiatric Association (2000). DSM_IV-TR Diagnostic and statistical manual of mental disorders (4a. ed.). Washington, DC, EE. UU.: American Psychiatric Association

AA.VV. (2007). Violencia escolar. El maltrato entre iguales en la ESO. Informe de la Oficina del defensor del Pueblo. Madrid

Avilés, J. M. y Monjas, I. (2005). Estudio de incidencia de la intimidación y el maltrato entre iguales en la educación secundaria obligatoria mediante el se establece con los progenitores está favoreciendo no solo la aparición, sino el mantenimiento de conductas de riesgo.

Es de destacar que se trata de una alumna que se encuentra rechazada dentro del grupo-aula, lo que puede estar propiciando la adopción de conductas desafiantes y violentas (Bender y Lösel, 2011), además de acarrear consecuencias negativas, no solo a nivel personal, sino también académico (García, Sureda y Monjas, 2010). En el caso que nos ocupa existen determinados problemas de inadaptación personal, escolar y familiar, especialmente la discrepancia educativa entre el padre y la madre y las malas relaciones con éste, que pueden estar en el origen de estas inadaptaciones. A nivel académico presenta fracaso escolar que se une a otros problemas de conducta como el consumo de sustancias adictivas e incurrir en actos temerarios y peligrosos, que entendemos precisan de un tratamiento psicológico específico (Espada y Méndez, 2002).

La propuesta de intervención que presentamos parte de la evaluación detallada del grupo-aula y especialmente del sujeto destacado en situación de riesgo, y por tanto del conocimiento de los factores que lo favorecen, lo que nos ha permitido diseñar el programa centrado en minimizar la acción de esos factores. Proponemos una intervención sistémica orientada hacia el sujeto y su contexto, entendiendo por éste el grupo aula y el núcleo familiar. Las estrategias van dirigidas a ambos ambientes y se centran en cómo mejorar la calidad de las relaciones y el establecimiento de normas claras y compartidas, que favorezcan la responsabilidad y la participación como estrategia básica para conseguir una respuesta efectiva.

En cuanto a las limitaciones del estudio, entendemos que sería conveniente incluir el análisis de la muestra en su conjunto desde la perspectiva de los factores de riesgo personal y familiar y adaptación que permitiera formular un modelo explicativo de estas conductas, así como ampliar la evaluación familiar y escolar desde la perspectiva de los padres y profesores. Del mismo modo sería conveniente avanzar en el estudio de los factores de protección ante los riesgos. Futuros estudios deberían ampliar la muestra para la propuesta de intervención así como los resultados de la misma, aunque debemos tener en cuenta que el presente trabajo está centrado en un grupo-aula y en el sujeto agresor. No obstante, consideramos que sería de interés contemplar no solo a los sujetos agresores, sino también a las víctimas y a los observadores del bullying.

cuestionario CIMEI (Avilés, 1999)-Cuestionario sobre Intimidación y Maltrato Entre Iguales-. Anales de psicología, 21 (1), 27-41

Becoña, E. (2000). Los adolescentes y el consumo de drogas. Papeles del Psicó$\log 0,77,25-32$.

Becoña, E., López, A., Fernández del Río, E., Martínez, U., Fraga, J., Osorio, Arrojo, M., López, F. y Domínguez, M. N. (2011). ¿Tienen una personalidad distinta los adolescentes consumidores de psicoestimulantes? Psicothema, 23 (4), 552-559 
Bender, D. and Lösel, F. (2011). Bullying at school as a predictor of delinquency, violence and other anti-social behaviour in adulthood. Criminal Behaviour and Mental Health, 21, 99-106.

Cava, M. J., Murgui, S. y Musitu, G. (2008). Diferencias en factores de protección del consumo de sustancias en la adolescencia temprana y media. Psicothema, 20 (3), 389-395

Cerezo, F. (2001). Variables de personalidad asociadas en la dinámica bullying. (agresores versus víctimas) en niños y niñas de 10 a 15 años. Anales de Psicología, 17 (1), 37-44

Cerezo, F. (2002). Test Bull- S. Test de Evaluación de la Agresividad entre Escolares. Madrid/ Bizkaia: Albor-Cohs

Cerezo, F. (2006). Violencia y victimización entre escolares. El bullying: estrategias de identificación y elementos para la intervención a través del Test Bull-S. Revista Electrónica de Investigación Psicoeducativa, 9 (4), 333-352.

Cerezo, F. (2009a). Bullying: Análisis de la situación en las aulas españolas. International Journal of Psychology and Psychological Therapy, 9 (3), 383-395

Cerezo, F. (2009b). La violencia en las aulas. Análisis y propuestas de intervención. Madrid: Pirámide

Cerezo, F and Ato, M. (2005). Bullying in Spanish and English pupils. A sociometric perspectiva using the Bull-S questionnaire. Educational Psychology, 25(4), 353-368

Cerezo, F. and Ato, M. (2010). Social status, gender, classroom climate and bullying among adolescents pupils. Anales de Psicología, 26 (1), 137-144

Cerezo, F.; Calvo, A. R. y Sánchez, C. (2011). El programa CIP para la intervención especifica en bullying. Madrid: Pirámide

Cerezo, F. y Méndez, I. (2009). Adolescentes, agresividad y conductas de riesgo de salud: análisis de variables relacionadas. International Journal of Developmental and Educational Psychology, 1(1), 217-226.

Cerezo, F., Méndez, I. y Rabadán, R. (2009). Encuesta para Estudiantes de Enseñanzas Secundarias. No publicado

Delegación del Gobierno para el Plan Nacional sobre Drogas (DGPNSD) (2008). Estudes 2008. Madrid: Ministerio de Sanidad y Política Social

Delegación del Gobierno para el Plan Nacional sobre Drogas (DGPNSD) (2009). Informe de la Encuesta Estatal sobre Uso de Drogas en Estudiantes de Enseñanzas Secundarias (ESTUDES) 2008. Madrid: Ministerio de Sanidad y Política Social

Díaz-Aguado, M. J. (2006). Programas de prevención del racismo y la violencia en los jóvenes. Madrid: Pearson

Estevez, E. and Emler, N. P. (2011). Assessing the links among adolescent and youth ofender, antisocial behavior, victimization, drug use, and gender. International Journal of Clinical and Health Psychology, 11(2), 269-289

Espada, J. P. y Méndez, F. X. (2002). Prevención del abuso del alcobol y del consumo de drogas de sintesis. Programa SALUDA. Madrid: Pirámide

Espada, J. P., Pereira, J. R. y García-Fernández, J.M. (2008). Influencia de los modelos sociales en el consumo de alcohol de los adolescentes. Psicothema, 20, 531-537.

Farrington, D. (2005). Childhood origins of the antisocial behaviour. Clinical Psychology and Psychotherapy, 12, 177-190

Farrington, D. and Ttofi, M. (2011). Bullying as a predictor of offending, violence and later outcomes. Criminal Behaviour and Mental Health, 21, 9098.

Fernandez, I., Villaoslada, E. y Funes, S. (2002). Conflicto en el centro escolar. El modelo de "alumno ayudante" como estrategias de intervención educativa. Madrid. Catarata.

Inglés, C. J., Delgado, B., Bautista, R., Torregrosa, M., Espada, J., GarcíaFernández, J.M., Hidalgo, M. y García-López, L. (2007). Factores psicosociales relacionados con al consumo de alcohol y tabaco en adolescentes españoles. International Journal of Clinical and Health Psychology, 7(2) 403-420

Luengo, M. A., Otero, J. M., Romero, E., Gomez, J. A.. y Tavares, E. T. (1999). Análisis de ítems para la evaluación de la conducta antisocial. Un estudio transversal. Revista Internacional de Pedagogía, 1, 21-36.

Lösel, F. and Bender, D. (2011). Emotional and antisocial outcomes of bullying and victimization at school: a follow-up from childhood to adolescence. Journal of aggression, conflict and peace research, 3 (2), 89-96
Garaigordobil, M. y Oñederra, J. A. (2008). Estudios epidemiológicos sobre la incidencia del acoso escolar e implicaciones educativas. Revista de Informació Psicológica, 94, 14-35.

García, F. J., Sureda, I. y Monjas, I. (2010). El rechazo ente iguales en la educación primaria: una panorámica general. Anales de Psicología, 26 (1), 122-136

Gázquez, M., García del Castillo, J. A. y Espada, J. P. (2011) Eficacia diferencial de dos programas de prevención escolar sobre el consumo de tabaco, según el tipo de aplicador. Psicothema, 23 (4), 537-543

Hernández, P. (2004). TAMAI Test autoevaluativo multifactorial de adaptación infantil. Madrid: TEA

Instituto de Evaluación (2011). Evaluación General de Diagnóstico 2010. Educación Secundaria Obligatoria. Segundo Curso. Informe de Resultados. Ministerio de Educación: Madrid

Kim, M. J., Catalano, R. F., Haggerty, K. P. and Abbott, R. D. (2011). Bullying at elementary school and problem behaviour in young adulthood: A study of bullying, violence and substance use from age 11 to age 21 . Criminal Behaviour and Mental Health, 21, 136-144

López, J. R. y López, C. (2008). Conducta antisocial y delictiva en la adolescencia. Murcia: Edit.um

Méndez, I. y Cerezo, F. (2010). Bullying y factores de riesgo para la salud en estudiantes de secundaria. European Journal of Education and Psychology, 3 (2), 209-218

Méndez, I. y Cerezo, F. (2011). Bullying y variables interpersonales en la adolescencia relacionadas con el riesgo para el consumo de drogas. International Journal of Developmental and Educational Psychology, 2 (1), 89-97

Moreno, D., Estévez, E., Murgui, S. y Musitu, G. (2009). Relación entre el clima familiar y el clima escolar: el rol de la empatía, la actitud hacia la autoridad y la conducta violenta en los adolescentes. International Journal of Psychology and Psychological Therapy, 9 (1), 123-136

Monjas. M. I. (2000). Programa de enseñanza de habilidades sociales para niños en edad escolar(PEHIS). Madrid: CEPE

OCDE (2009). Creating Effective Teaching and Learning Environments. First Results from TALIS. Extraído el 23 de junio de 2010 desde: http://www.oecd.org/dataoecd/17/51/43023606.pdf

Olweus, D. (1993). Bullying at school. What we know and what we can do. Oxford, U.K.: Blackwell. (Traducción: Conductas de acoso y amenaza entre escolares. Madrid: Morata. 1998).

Ortega, R. y Mora-Merchán, J. (2005). Conflictividad y violencia escolar. Sevilla: Diada.

Pérez, M. C. y Gázquez, J. J. (2010). Variables relacionadas con la conducta violenta en la escuela según los estudiantes. International Journal of Psychology and Psychological Therapy, 10 (3), 427-437

Renda, J., Vassallo, S. and Edwards, B. (2011). Bullying in early adolescence and its association with anti-social behaviour, criminality and violence 6 and 10 years later. Criminal Behaviour and Mental Health, 21, 117-127

Ruiz-Juan, F. y Ruiz-Risueño, J. (2011). Variables predictoras de consumo de alcohol entre adolescentes españoles. Anales de Psicología, 27 (2), 350359

Sánchez, M. I., Moreno, M. C., Muñoz, M. V. y Pérez, J. P. (2007). Adolescencia, grupo de iguales y consumo de sustancias. Un estudio descriptivo relacional. Apuntes de Psicología, 25 (3), 305-324.

Salmivalli, C. (2010). Bullying and the peer group: A review. Aggression and Violent Behavior, 15, 112-120

Secades, R., Carballo, J. L., Fernández-Hermida, J. R., García, O. y García, E. (2006). Cuestionario de factores de riesgo interpersonales para el consumo de drogas en adolescentes (FRIDA). Madrid: TEA.

Serrano, A. y Iborra, I. (2005). Violencia entre compañeros en la escuela. Centro Reina Sofía para el estudio de la violencia. Valencia: Serie Documentos

Torrente, G. y Rodríguez, A. (2004). Características sociales y familiares vinculadas al desarrollo de la conducta delictiva en pre-adolescentes y adolescentes. Cuadernos de Trabajo Social, 17, 99-115.

Trianes, M. V. y Fernandez-Figarés, C. (2001). Enseñar a ser persona y a convivir. Un programa para secundaria. Bilbao: Desclee de Brower.

(Articulo recibido: 18/5/2011; revisado: 23/11/2011; aceptado: 30/11/2011) 